\title{
Demons of the mind: The 'psy' sciences and film in the long I960s
}

History of the Human Sciences (c) The Author(s) 2021

(c) (i)

Article reuse guidelines: sagepub.com/journals-permissions DOI: 10.1 I 77/0952695। 2 II 028525 journals.sagepub.com/home/hhs

@SAGE

\author{
Tim Snelson
}

University of East Anglia, UK

William R. Macauley

University of Manchester, UK

\begin{abstract}
This introduction provides context for a collection of articles that came out of a research symposium held at the Science Museum's Dana Research Centre in 2018 for the 'Demons of Mind: the Interactions of the 'Psy' Sciences and Cinema in the Sixties' project. Across a range of events and research outputs, Demons of the Mind sought to map the multifarious interventions and influences of the 'psy' sciences (psychology, psychiatry, and psychoanalysis) on film culture in the long 1960s. The articles that follow discuss, in order: critical engagement with theories of child development in 1960s British science fiction; the 'horrors' of contemporary psychiatry and neuroscience portrayed in the Hollywood blockbuster The Exorcist (1973); British social realist filmmakers' alliances with proponents of 'anti-psychiatry'; experimental filmmaker Jane Arden's coalescence of radical psychiatry and radical feminist techniques in her 'psychodrama' The Other Side of the Underneath (1973); and the deployment of film technologies by 'psy' professionals during the post-war period to capture and interpret mother-infant interaction.
\end{abstract}

\section{Keywords}

cinema, film, psychiatry, psy sciences, television

This special issue emerged from a symposium for the Arts and Humanities Research Council-funded project 'Demons of Mind: the Interactions of the 'Psy' Sciences and

\section{Corresponding author:}

Tim Snelson, University of East Anglia, School of Art, Media and American Studies, Norwich Research Park, Norwich, Norfolk, NR4 7TJ, UK.

Email: t.snelson@uea.ac.uk 
Cinema in the Sixties' (AH/P005136/1), hosted at the Science Museum's Dana Research Centre in September 2018. With the Demons of the Mind project, we sought to provide the first interdisciplinary account of the complex contestations and cross-pollinations of the 'psy' sciences (psychology, psychiatry, psychoanalysis) and cinema in the 'long 1960s' (Marwick, 2005), making an original contribution at the intersection of the history of science and medicine, film and media studies, and science communication. This special issue speaks to these interdisciplinary aims but also extends them to incorporate a range of academic experts undertaking complimentary research on the intersecting fields of mental health and media during the mid-1950s to early-1970s.

We identify the 'long 1960s' as a period of intense struggles over competing claims and understandings of the human mind, with psychologists, psychiatrists, and psychoanalysts in deep conflict or, in some instances, uneasy alliances. This was the period of professional and public disputes over key developments in the psy professions, such as the clinical use of antipsychotic and psychotropic drugs (Moncrieff, 2013); theories on the role of genetics and personality used to diagnose and treat behaviour labelled as deviant, psychotic, or criminal (Hakeem, 1958; Steinfels and Levine, 1980); theories of child development and attachment (Vicedo, 2013); theories of conformity, obedience, and bystander apathy (Darley and Latané, 1968); psychology's contribution to defining sexuality, gender, and women's oppression (Herman, 1995); the popularisation of psychotherapy (Zaretsky, 2004); and the emergence of the 'anti-psychiatry' movement (Staub, 2011; Wall, 2017). It was also a period in which cinema and other popular media became preoccupied with the 'demons of the mind', with horror, science fiction, crime, and thriller films, in particular, becoming key ways in which psychological concepts were disseminated as well as debated within the public sphere. ${ }^{1}$ Hollywood and British cinema invested heavily, financially and creatively, in exploring psychological ideas in overlapping cycles of genre films. Many were Anglo-American co-productions featuring the two countries' most celebrated directors and stars (William Wyler, Otto Preminger, Joseph Losey, Alfred Hitchcock, Lawrence Olivier, Noël Coward, Audrey Hepburn) and luminaries of New Hollywood and the British New Wave (Robert Altman, Peter Bogdanovich, Jack Clayton, Karel Reisz, Mia Farrow).

While there has been some interesting recent work on Hollywood depictions of psychiatric and psychotherapeutic practices in this period (DeAngelis, 2018; Halliwell, 2013), the 'Demons of the Mind' project moved beyond this persistent focus on representation to consider the situated interactions and sharing of expertise by professionals working within and across the medical and media spheres in the UK and US. For example, our research demonstrated that the period from the mid-1950 to the mid-1970s was one of significant coproduction of scientific knowledge, when both orthodox and progressive psychiatrists, child psychologists, and leading psychoanalysts were employed as paid consultants on films and television; psy professionals were directly involved in making confidential decisions on censorship, classification, and revision of scripts for the British Board of Film Censors (Snelson and Macauley, 2020); a New York psychoanalyst was appointed to head up America's reoriented Classification and Rating Administration as it shifted from a religious to a psychiatric basis for its decision-making; mental health organisations launched their own 
film-making training and production wings; Hollywood films dealing with mental institutions were screened in Congress and cited in the passing of major mental health legislation; and psychologists took up roles as film critics for the middlebrow press because of the increasing prevalence of psychological and psychedelic themes on screen.

The articles in this special issue speak to our project's objective of mapping the complex diffusions and interactions between the psy sciences, cinema, and wider culture, but also expand the types of clinical-creative interactions, categories of film, and author expertise marshalled in our 'Demons of the Mind' research. The first two articles focus on popular film genres, demonstrating cinema's complex engagements and reception within shifting and converging political, scientific, and cultural contexts. Laura Tisdall's article explores 1960s British science fiction and horror's 'extraordinary' child. Tisdall sees this thematic trope as a convergence of anxieties about nuclear apocalypse and its impact on future generations, emerging from contemporary discourse in developmental psychology and early neuroscience that effectively prioritised 'normal' children and pathologised those who developed at what was believed to an 'abnormal' rate - too fast or too slow. As Tisdall shows, rather than being put off by these normalising discourses, adolescents unexpectedly became a key market for these films and used them to negotiate and articulate their personal nuclear anxieties and psychological experiences. Amy Chambers' article also focuses on horror and one of cinema's most (in) famous 'extraordinary children', Regan MacNeil. Looking at the other end of the long 1960s through the lens of the Hollywood blockbuster The Exorcist (1973), Chambers highlights the film's destabilising of medical knowledge in the context of a wider scepticism of grand narratives and the hegemonic authority of medical science, religion, and politics. It is not the 'extraordinary' child but the extraordinarily gruelling psychiatric and neuroscientific procedures she (and we) must endure that are the subject of horror (and the viscerally disturbing prompt for audiences to faint and vomit in film theatres).

The next two articles move outside popular genre films to explore radical and experimental film-makers' engagements with key actors and ideas within the British 'anti-psychiatry' movement. Tim Snelson's article looks at the creative collaborations between radical filmmakers (Ken Loach, Tony Garnett, David Mercer) and radical psychiatrists (R. D. Laing, Aaron Esterson, David Cooper) on the BBC television drama In Two Minds (1967) and its cinema remake Family Life (1971). This diachronic analysis challenges ideas of the ubiquity of Laingian ideas in the late 1960s and of a clear split within British psychiatry, highlighting the vital roles these films played not only in bringing 'anti-psychiatry' to the purview of the media and the public, but also in providing models for the wider mental health field to critically engage with them more effectively. Sophia Satchell-Baeza's article explores the work of experimental film-maker Jane Arden in the early 1970s, specifically her debut feature film, The Other Side of the Underneath (1973). Satchell-Baeza situates the creative processes and resultant film through the conceptual and embodied framework of psychodrama - as a form of converging therapeutic release and consciousness raising - which aligns countercultural and radical feminist tactics. While Arden drew upon the ideas and practices of colleague Laing, including the use of LSD psychotherapy, her creative works also countered anti-psychiatry's patriarchal structures and failings.

The final article in our collection did not emerge directly from the 'Demons of the Mind' symposium but was brought to our attention by HHS editor Rhodri Hayward as 
a piece that would align with and enhance the scope of our collection. Katie Joice's article explores the post-war use of film technologies by psy professionals to capture and interpret mother/infant interaction. This 'cinematic microanalysis' drove the technologically driven form of maternalism that served to fetishise and strictly domesticise the formative powers of mothers. We concur with the editor's suggestion and are delighted that the inclusion of Joice's article takes our special issue into new and exciting territory that completes the circle of 'Demons of the Mind's' mapping of interactions between and convergence of film-making and psychiatric expertise: from popular film-makers marshalling the latest psychological and neuroscientific ideas to enhance the authenticity or ambivalence of their films, to creative collaborations between radical media and mental health practitioners, to film-making as liberatory therapy, and finally to film-making as a diagnostic tool that provided the epistemological foundation for infant psychiatry.

\section{Declaration of conflicting interests}

The authors declared no potential conflicts of interest with respect to the research, authorship, and/ or publication of this article.

\section{Funding}

The authors disclosed receipt of the following financial support for the research, authorship, and/or publication of this article: This work was supported by the Arts and Humanities Research Council (grant number AH/P005136/1) and constitutes part of the project 'Demons of the Mind: The Interactions of the "Psy" Sciences and Cinema in the Sixties'. The project website can be found at: http://www.psychologyandcinema.com/.

\section{ORCID iD}

Tim Snelson (iD https://orcid.org/0000-0002-8282-2432

\section{Note}

1. The project is named after the 1972 British Hammer Horror film Demons of the Mind, which combined classic Gothic horror elements and X-rated gore with the 'central very serious idea of looking at the life of [German physician Franz] Mesmer and the origins of looking at psychopathic behaviour and hysteria and treating them through hypnotism' (Peter Sykes, director's commentary, in Sykes, 2002[1972]).

\section{References}

Darley, J. and Latané, B. (1968) 'Bystander Intervention in Emergencies: Diffusion of Responsibility', Journal of Personality and Social Psychology 8(4): 377-83.

DeAngelis, M. (2018) Rx Hollywood: Cinema and Therapy in the 1960s. New York, NY: State University of New York Press.

Hakeem, H. (1958) 'A Critique of the Psychiatric Approach to Crime and Correction', Law and Contemporary Social Problems 23(4): 650-82.

Halliwell, M. (2013) Therapeutic Revolutions: Medicine, Psychiatry and American Culture, 194570. New Brunswick, NJ: Rutgers University Press. 
Herman, E. (1995) The Romance of American Psychology: Political Culture in the Age of Experts. Berkeley, CA: University of California Press.

Marwick, A. (2005) 'The Cultural Revolution of the Long Sixties: Voices of Reaction, Protest, and Permeation', International History Review 27(4): 780-806.

Moncrieff, J. (2013) 'Magic Bullets for Mental Disorders: The Emergence of the Concept of an "Antipsychotic" Drug', Journal of the History of the Neurosciences 22(1): 30-46.

Snelson, T. and Macauley, W. (2020) "The Influence of "Psychiatrist Friends" on British Censorship in the 1960s', Journal of British Cinema and Television 17(4): 473-500.

Staub, M. (2011) Madness Is Civilization: When the Diagnosis Was Social, 1948-80. Chicago, IL: University of Chicago Press.

Steinfels, M. O. and Levine, C. (1980) 'The XYY Controversy: Researching Violence and Genetics', The Hastings Center Report 10(4): 1-31.

Sykes, P., director (2002[1972]) Demons of the Mind [DVD]. Anchor Bay.

Vicedo, M. (2013) The Nature and Nurture of Love: From Imprinting to Attachment in Cold War America. Chicago, IL: University of Chicago Press.

Wall, O. (2017) The British Anti-Psychiatrists: From Institutional Psychiatry to the Counter-Culture, 1960-71. London: Routledge.

Zaretsky, E. (2004) Secrets of the Soul: A Social and Cultural History of Psychoanalysis. New York, NY: Vintage.

\section{Author biographies}

Tim Snelson is a senior lecturer in media history at the University of East Anglia. His research addressing the relationship between media and social history has been published in journals including Media History and Cultural Studies and in a monograph titled Phantom Ladies: Hollywood Horror and the Home Front (Rutgers University Press, 2015).

William R. Macauley is a lecturer at the University of Manchester and senior research associate at the Science Museum, London. He has an academic background and research experience in psychology and the history of science, technology, and medicine, and has been published in journals including History of Technology and the Journal of Sonic Studies. 